IJBPAS, December, 2021, 10(12): 4371-4377

ISSN: $2277-4998$

International Journal of Biology, Pharmacy and Allied Sciences (IJBPAS)

'A Bridge Betusen Caboratory and QRendo'

WwW.ijbpas.com

\title{
DESIGN, SYNTHESIS AND X-RAY SINGLE CRYSTALLOGRAPHIC STRUCTURE OF 2-(1,3-DITHIOLAN-2-YL)-6-(HYDROXYMETHYL)-4- METHYLPHENOL
}

\author{
SAHA SK \\ Department of Physics, Sambhu Nath College, Labpur, Birbhum 731303, West Bengal, India \\ *Corresponding Author: Subrata Kumar Saha: E Mail: subratasaha.bolpur@gmail.com \\ Received 17 ${ }^{\text {th }}$ July. 2021; Revised 16 ${ }^{\text {th }}$ Aug. 2021; Accepted $11^{\text {th }}$ Nov. 2021; Available online $1^{\text {st }}$ Dec. 2021 \\ https://doi.org/10.31032/IJBPAS/2021/10.12.5754
}

\begin{abstract}
4-methylphenol based compound, 2-(1,3-dithiolan-2-yl)-6-(hydroxymethyl)-4-methylphenol (L2) was designed, synthesised and characterised using x-ray single crystallographic tools. The tittles compound was synthesized via two steps where the first step involves the formation of mono-blocked compound, L1. L1 compound was initially synthesized by blocking of one aldehyde group out of two symmetrically positioned aldehyde group of 2,6-diformyl-4-methylphenol. The second step involves the mild reduction of unblocked-aldehyde group using $\mathrm{NaBH}_{4}$. This process involved interesting synthetic methodology. X-ray single crystal data were collected using Mo-Ka ( $\lambda=0.7107 \AA$ ) radiation on a SMART APEX II diffractometer equipped with CCD area detector. The tittles compound, L2 crystallises in monoclinic crystal system with P $2{ }_{1} / \mathrm{c}$ space group when allowed to evaporate the desired organic solvent.
\end{abstract}

Keywords: X-ray single crystallography, 4-methylphenol, reduction, $\mathrm{NaBH}_{4}$ \section{INTRODUCTION}

Autism spectrum disorder (ASD) is known as a neurodevelopmental disorder. It becomes apparent in early childhood and also disturbs all the characteristics of a child's development. It is often described by the impaired social interaction and 
communication, as well as by the restricted patterns of interest [1]. It displays a broad variety of clinical signs, developmental trajectory, severity, and treatment response. 4-methylphenol and its derivatives, an organic molecule belonging to the cresol class of aromatic compounds has recently become the targeting molecules of our interest as it possibly involved in ASD [2]. Environmental exposure of p-cresol is relatively very usual and its absorption can occur through the skin and the respiratory tract. Being a lipophilic nature of this compound, it can easily travel in the blood stream through the formation of proteinbound state [3]. Then, p-cresol and its derivates e.g. p-cresylsulfate and pcresylglucuronide are then filtered at the glomerular level and can be found in the urines in small amounts $[\mathbf{4}, \mathbf{5}]$. Thus, $\mathrm{p}$-cresol and its derivatives are the most interesting molecules to explore the various activity.

Here in this research, I have designed and synthesized a 4-methylphenol (p-cresol) based compound, 2-(1,3-dithiolan-2-yl)-6(hydroxymethyl)-4-methylphenol (L2). The titile compound was characterised using $\mathrm{x}$ ray single crystallographic tools. It was synthesized via two steps where the first step involves the formation of mono-blocked compound, and then mild reduction using
$\mathrm{NaBH}_{4}$ was performed to generate the targeted compound. X-ray single crystal data were collected using Mo-Ka $(\lambda=0.7107 \AA)$ radiation on a SMART APEX II diffractometer equipped with $\mathrm{CCD}$ area detector. The tittles compound, L2 crystallises in monoclinic crystal system with P $21 / \mathrm{c}$ space group when allowed to evaporate the desired organic solvent.

\section{EXPERIMENTAL SECTION}

\section{MATERIALS AND METHODS}

All reagents, chemicals and solvents were purchased from Sigma. FTIR measurement was performed in PerkinElmer L120-00A spectrometer using $\mathrm{KBr}$ pellet. A Qtof Micro YA263 mass spectrometer was taken for recording electron spray ionization (ESI) mass spectrometry. A Bruker Advance DPX 400 was used for collecting NMR data.

\section{SYNTHESIS OF COMPOUND L1}

The compound L1 was prepared using slight modification of the previously described procedure [6]. 1,2-ethanediol (0.282 g, 3.0 mmol) was added drop wise to a solution of 2,6-diformyl-4-methylphenol (1.476 g, 9.0 $\mathrm{mmol}$ ) in $50 \mathrm{~mL}$ chloroform under vigorous stirring at $0{ }^{\circ} \mathrm{C}$ over a period of $1.5 \mathrm{~h}$. Then, catalytic amount of iodine was added and to this mixture and it was allowed to stir further $30 \mathrm{~min}$ at room temperature. The progress of the reaction was checked by TLC (ethyl 
acetate $5 \%$ in petroleum ether). After completion of the reaction $0.1 \mathrm{M} \mathrm{Na}_{2} \mathrm{~S}_{2} \mathrm{O}_{3}$ $(20 \mathrm{~mL})$ and $10 \% 25 \mathrm{~mL} \mathrm{NaOH}$ were added to this reaction mixture. After washing the organic layer with water, the solvent was removed under reduce pressure and purified with 5\% ethyl acetate in petroleum ether (v/v) to give compound L1 as an light yellow solid in a good yield (isolated yield 76\%). ${ }^{1} \mathrm{H}$ NMR (400 MHz, $\left.\mathrm{CDCl}_{3}\right): \delta 2.31(\mathrm{~s}, 3 \mathrm{H})$, 3.33-3.40 (m, 4H), 3.55-3.59 (t, 4H), $6.00(\mathrm{~s}$, 1H), 7.11 (s, 1H), 7.77 (s, 1H), $9.80(\mathrm{~s}, 1 \mathrm{H})$, and $11.25(\mathrm{~s}, 1 \mathrm{H}) \cdot{ }^{13} \mathrm{C}\left(100 \mathrm{MHz}, \mathrm{CDCl}_{3}\right): \delta$ 20.7, 39.6, 47.2, 120.6, 129.5, 129.5, 133.7, 136.7, 156.7, and 196.7. HRMS (m/z) found 241.0369, calculated for $[\mathrm{M}+\mathrm{H}]^{+} 241.0357$ where $\mathrm{M}$ was $\mathrm{C}_{11} \mathrm{H}_{12} \mathrm{O}_{2} \mathrm{~S}_{2}$, compound L1.

\section{SYNTHESIS OF COMPOUND L2}

To a $20 \mathrm{~mL}$ methanolic solution of L1 (0.240 g, $1.0 \mathrm{mmol}), \mathrm{NaBH}_{4}(0.056 \mathrm{~g}, 1.5 \mathrm{mmol})$ is added pinch wise during $45 \mathrm{~min}$ with stirring. After complete addition of $\mathrm{NaBH}_{4}$, the reaction mixture was allowed to stir for another $4 \mathrm{~h}$ at room temperature. The progress of the reaction was monitored by TLC. After the completion of the reaction, the reaction mixture was extracted by DCM and washed many times till $\mathrm{NaBH}_{4}$ was removed completely. The separated organic layer was evaporated under reduced pressure and purified with $15 \%$ ethylacetate in petroleum ether $(\mathrm{v} / \mathrm{v})$ to give the compound L2 (isolated yield: 62\%). \%). X-ray quality single crystals were obtained by the slow evaporation of the methanolic solution after few days.

\section{X-RAY DATA COLLECTION AND STRUCTURE DETERMINATION}

Crystal data for L2 was summarised in Table 1. The diffraction experiments were carried out with a Bruker SMART CCD area detector diffractometer at $296 \mathrm{~K}$ for both the complexes using Mo $\mathrm{K} \alpha$ radiation $(\lambda=$ 0.71073) with a graphite crystal monochromator in the incident beam, necessary corrections were applied using SADABS from Bruker [7]. Fourier fullmatrix least-squares refinement methods based on $\mathrm{F}^{2}$, using SHELX-97 was used to refine all of the nonhydrogen atoms anisotropically in order to solve the structure [8]. WinGX package was also utilized for all of the calculations $[9,10]$. As per the deposition of the cif files to the Cambridge Crystallographic Data Centre, the codes were allocated as CCDC 2121956. 
<smiles>Cc1cc(C=O)c(O)c(C=O)c1</smiles>

2,6-Diformyl4-methylphenol i) 1,2-ethanedithiol $\mathrm{CHCl}_{3}, 0^{\circ} \mathrm{C}, 1.5 \mathrm{~h}$

ii) Cat. $\mathrm{I}_{2}, \mathrm{RT}, 30 \mathrm{~min}$

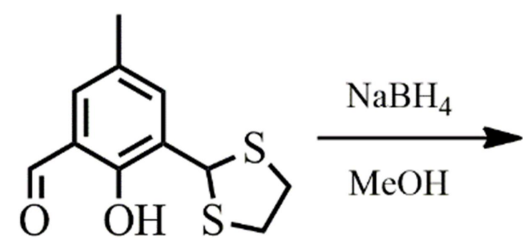

L1<smiles>Cc1cc(CO)c(O)c(C2SCCS2)c1</smiles>

L2

Scheme 1: Synthetic routes for the preparation of the final compound L2

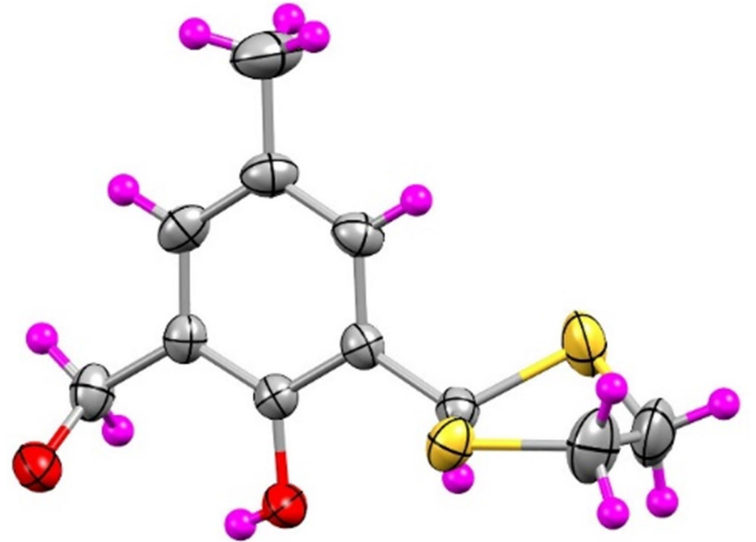

Figure 1: An ORTEP diagram (50\%) of the tittle compound, L2 with atom colour coding scheme. C: gray, O: red, S: yellow and $\mathrm{H}$ : magenta

Table 1: Crystallographic information for compound L2

\begin{tabular}{cc}
\hline & Compound L2 \\
\hline Chemical formula & C11 H14 O2 S2 \\
Crystal system & monoclinic \\
Space group & P 21/c \\
Formula weight & 242.36 \\
$a(\AA)$ & $11.097(2)$ \\
$b(\AA)$ & $7.908(2)$ \\
$c(\AA)$ & $14.488(3)$ \\
$\alpha\left({ }^{\circ}\right)$ & $89.92(3)$ \\
$\beta\left({ }^{\circ}\right)$ & $109.52(3)$ \\
$\gamma\left({ }^{\circ}\right)$ & $89.96(3)$ \\
$V\left(\AA^{3}\right)$ & $1198.3(5)$ \\
$Z$ & 1 \\
$D_{\text {calcd. }}($ gcm & -3 \\
$T\left(K^{\prime}\right)$ & 0.672 \\
F(000) & $296(2)$ \\
$\lambda(M o-K \alpha)$ & 256 \\
Collected reflns & 0.71073 \\
Independent reflns & 3650 \\
$\theta$ range (deg) & 2463 \\
R factor & $1.947-30.781$ \\
Goodness-of-fit & 0.0663 \\
\end{tabular}




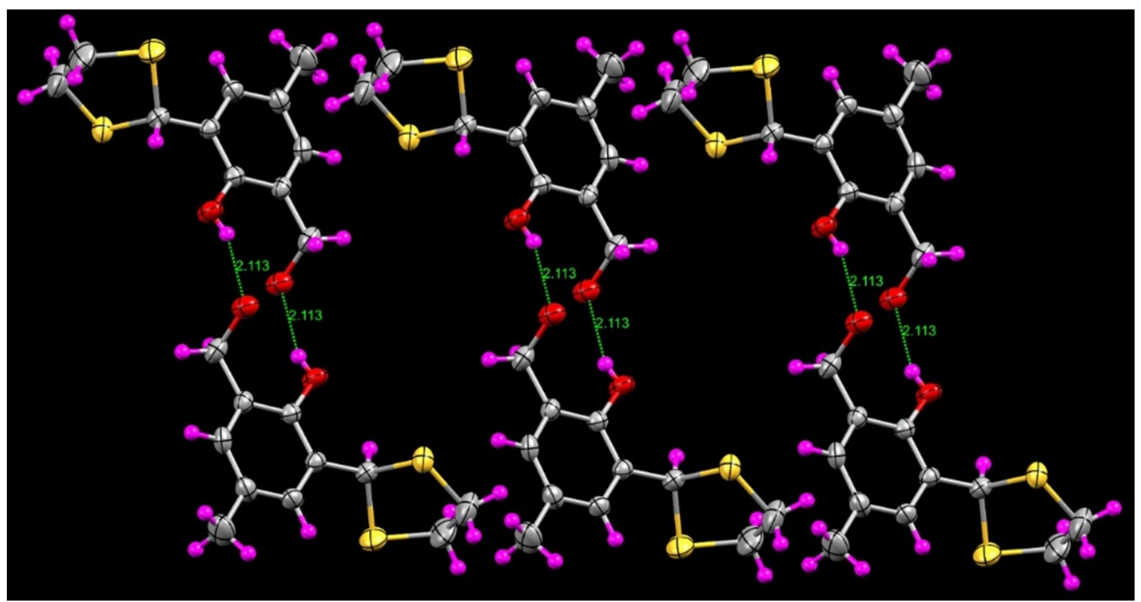

Figure 2: The crystal packing view of the title compound, L2, exhibits intermolecular H-bonding (green dots) between two molecules in an asymmetric unit

\section{RESULTS AND DISCUSSION}

The synthetic steps for the preparation of L2 are depicted in Scheme 1. Here, in the first step, 2,6-diformyl-4-methylphenol was reacted with one molecule of 1,2-ethanediol in such a way that it formed mono-blocked aldehyde product (L1). The reaction was performed in such a controlled way that the yield of mono product would be high enough. After that, the unblocked aldehyde was then reduced by mild reducing agent i.e. $\mathrm{NaBH}_{4}$ in methanolic solution at room temperature. X-ray quality single crystals were obtained by the slow evaporation of the methanolic solution after few days. The ORTEP diagram (50\%) of the final compound, L2, with colour coding scheme was shown in Figure 1. The tittle compound, L2, crystallized in the monoclinic crystal system, space group P 21 c. Crystallographic data were presented in Table 1. The crystallographic asymmetric unit of the tittle compound consists of two molecular units. These two molecules were found to position with close proximity through H-bonding interaction (Figure 2). The ' $\mathrm{O}$ ' atoms of alcoholic - $\mathrm{OH}$ and phenolic -OH group were participated intermolecularly with the other proximal molecular ' $\mathrm{O}$ ' atoms of the same type. The O-----H distance (H-bonding) was measures as $2.113 \AA$ and the participation O----O distance was $2.769 \AA$.

\section{CONCLUSION}

In conclusion, 2-(1,3-dithiolan-2-yl)-6(hydroxymethyl)-4-methylphenol was successfully designed, synthesised and characterised by x-ray single crystallographic analysis. The tittles compound was synthesized via two steps where the first step involves the formation of mono-blocked 
compound by blocking of one aldehyde group out of two symmetrically positioned aldehyde group of 2,6-diformyl-4-methylphenol. The second step involves the mild reduction of unblocked-aldehyde group using $\mathrm{NaBH}_{4}$. The x-ray quality single crystals were obtained by slow evaporation of the methanolic solution of the titled compound after few days. X-ray single crystal data were collected using Mo-Ka $(\lambda=0.7107 \AA)$ radiation on a SMART APEX-II diffractometer equipped with $\mathrm{CCD}$ area detector.

\section{REFERENCES}

[1] Diagnostic and statistical manual of mental disorders. 5th ed. Arlington (VA): American Psychiatric Publishing, 2013. https://doi.org/10.1176/appi.books.97 80890425596.

[2] m-/p-Cresol Category, Screening Information Data Set, Initial Assessment Report. Paris: UNEP Publications, OECD. 2003.

[3] Bergé-Lefranc D, Chaspoul, F, Calaf R, Charpiot P, Brunet P, Gallice P. Binding of $\mathrm{p}$-cresylsulfate and $\mathrm{p}$ cresol to human serum albumin studied by microcalorimetry. J Phys Chem B. 2010; 114(4):1661-1665. doi: $10.1021 /$ jp9059517.
[4] Bone E, Tamm A, Hill M. The production of urinary phenols by gut bacteria and their possible role in the causation of large bowel cancer. Am J Clin Nutr. 1976; 29(12):1448-1454. doi: 10.1093/ajen/29.12.1448.

[5] Renwick AG, Thakrar A, Lawrie CA, George CF. Microbial amino acid metabolites and bladder cancer: no evidence of promoting activity in man. Hum Toxicol. 1988; 7(3):267272.

doi: 10.1177/096032718800700307.

[6] Sarkar A, Chakraborty S, Lohar S, Ahmmed E, Saha NC, Mandal SK, Dhara K, Chattopadhyay P. A lysosome-targetable fluorescence sensor for ultrasensitive detection of $\mathrm{Hg}^{2+}$ in living cells and real samples. Chem Res Toxicol. 2019; 32(6):11441150.

https://doi.org/10.1021/acs.chemresto x.9b00005.

[7] Bruker. SMART, SAINT; Software Reference Manual Bruker AXSInc: Madison, Wisconsin, USA, 2000.

[8] Sheldrick GM, Shelxs97 and Shelx197 Programs for Crystallography; University of Göttingen: Germany, 1997.

[9] Farrugia LJ. Win $G X$ suite for smallmolecule single-crystal crystallography. 
Appl Crystallogr. 1999; 32:837-838.

https://doi.org/10.1107/S0021889899

006020.

[10] Sheldrick GM. A Short History of SHELX. Acta Crystallographica.

2008; A64:112-122.

http://dx.doi.org/10.1107/S0108767

307043930 . 